\title{
A Judicialização da Prescrição Medicamentosa no SUS ou o Desafio de Garantir o Direito Constitucional de ACESSo À AssistênCIa Farmacêutica
}

\author{
JURIDICAL PROCESS OF DRUGS PRESCRITION IN THE \\ BRAZILIAN PUBLICH HEALTH SYSTEM OR THE CHALLENGE OF \\ ENSURING THE CONSTITUTIONAL RIGHT TO DRUGS ACCESS
}

Oswaldo Yoshimi Tanaka ${ }^{(*)}$

O direito à saúde, garantido pela Constituição Federal de 1988, sem dívida, é um ganho em nosso processo democrático. A saúde como dever do Estado, financiado por um sistema público não contributivo permitiu explicitar a universalidade, a integralidade e a equidade como os princípios norteadores de nossa política de saúde. Nesse sentido, o poder executivo, nas três esferas de governo tem envidado esforços para viabilizar a garantia deste direito constitucional.

(*) Professor titular do Departamento de Prática de Saúde Pública da Faculdade de Saúde Pública da Universidade de São Paulo, médico sanitarista, mestre e doutor em Saúde Pública. Pósdoutorado na Universidade de Bristol, Inglaterra. E-mail: <oytanaka@usp.br>. 
Dentre as distintas estratégias implementadas, podemos destacar a assistência farmacêutica que, pela sua importância no processo de resolução dos problemas de saúde, tem sido paulatinamente organizada visando garantir a resolutividade necessária ao processo de atenção à saúde.

O eixo norteador da assistência farmacêutica no Sistema único de Saúde (SUS) pauta-se pela garantia do fornecimento de medicamentos de acordo com uma definição técnica de adequação e de custo/efetividade.

Para tanto, as normas vigentes estabelecem três grandes grupos de medicamentos:

1. Estratégicos - utilizados para tratamento das doenças de perfil endêmico, cujo controle e tratamento tenham protocolo e normas estabelecidas e que tenham impacto socioeconômico, tais como: tuberculose, hanseníase, Endemias Focais, DST/AIDS e sangue e hemoderivados. No total, são 125 apresentações de medicamentos para dispensação.

2. Básico - essenciais para a garantia da atenção básica referente a patologias mais prevalentes. São dispensados na porta de entrada do sistema de saúde e incluem 87 medicamentos em distintas apresentações.

3. Excepcionais - medicamentos para o tratamento de doenças específicas, que atingem um número limitado de pacientes, os quais, na maioria das vezes, utilizam-nos por períodos prolongados. Compreende um conjunto de doenças bem definidas com protocolos clínicos, em que os medicamentos dispensados se baseiam em custo efetividade e comprovação terapêutica validada. Neste grupo, estão patologias como: doença de Gaucher, doença de Parkinson, Alzheimer, hepatites $\mathrm{B}$ e $\mathrm{C}$, pacientes renais crônicos, transplantados, portadores de asma grave, anemia, dentre outras. A listagem desses medicamentos abrange 226 apresentações.

A estratégia de implementação da assistência farmacêutica no SUS engloba de maneira racional e lógica a definição de grupos de medicamentos direcionados a problemas de saúde, baseado em sua complexidade, perfil epidemiológico e relacionamento com os distintos níveis de atenção.

O planejamento da assistência farmacêutica no SUS busca garantir o acesso a medicamentos da forma mais racional possível envolvendo e responsabilizando as três esferas de governo, utilizando as normalizações e, principalmente, os protocolos clínicos para atingir a efetividade esperada nos tratamentos. Este planejamento é identificado na atenção médica, brindada pelos distintos níveis do sistema de saúde.

Nesse contexto, a decisão judicial do Supremo Tribunal Federal é um exemplo para problematizar essa questão. Trata-se de uma medida liminar 
que obriga o Governo do Estado do Rio Grande do Norte, decisão SS 3145/ $\mathrm{RN}$, a fornecer a um cidadão portador de hipertensão arterial, as drogas: Digoxina, Atorvastatina, Triflusal e Propatilnitrato.

Evidencia-se neste despacho que a preocupação do Judiciário foi garantir o acesso a estas medicações, consideradas essenciais e um direito do cidadão. Tendo como base este objetivo e intencionalidade, podemos nos arriscar a analisar cada um dos medicamentos em si, e a seguir as repercussões deste tipo de procedimento para a concretização dos princípios do SUS.

A Digoxina é um digitálico, cuja ação principal é o aumento da forca dos batimentos cardíacos, permitindo que a "bomba" coração funcione meIhor. Tem uma indicação específica em casos de hipertensão arterial e faz parte dos medicamentos da atenção básica definidos pelo SUS para dispensação gratuita na atenção básica. Portanto, sendo de uso normalizado para uma patologia de alta prevalência e de dispensação gratuita na rede básica, em princípio não deveria ser necessária uma ação judicial para seu provimento.

A Atorvastatina, um lipemiante, destinado ao controle do colesterol, faz parte dos medicamentos excepcionais definidos pelo SUS. Como explicado anteriormente, é uma categoria de medicamento para a qual o poder público, por meio de seus técnicos e de assessoria especializada, definiu protocolos de atenção e procedimentos terapêuticos baseados em evidências clínicas e estudos de custo/efetividade. A indicação está bem estabelecida e padronizada e a respectiva dispensação devidamente controlada por Autorização de Procedimentos de Alta Complexidade (APAC). Neste caso específico, o referido usuário teria de passar por um centro especializado que, ao realizar a avaliação clinica e se de acordo com o protocolo definido, proveria o referido medicamento.

O Triflusal é um anticoagulante de longa duração. Os anticoagulantes fazem parte da padronização de medicamentos da atenção básica. Porém, a droga padronizada é o ácido salicílico que, de acordo com as evidências clínicas, apresenta resultados plenamente adequados para o processo de manutenção da fluidez da viscosidade sangüínea, evitando as conseqüências da hipertensão arterial. Portanto, neste caso o que se tem é um medicamento alternativo ao padronizado, cuja justificativa não podemos aquilatar com precisão tendo em vista não dispormos de todos os dados clínicos e laboratoriais que permitam analisar a pertinência ou a impossibilidade de substituição deste em detrimento do medicamento padronizado.

O Propatilnitrato é um vasodilatador coronariano de ação prolongada, indicado para dores anginosas que podem acometer pacientes com hipertensão arterial em crises hipertensivas. Como a medicação anterior, é um derivado mais recente, cujos efeitos colaterais seriam mais amenos do que 
o medicamento padronizado na atenção básica, a Isossorbida. Ao não dispormos de informações dos antecedentes do paciente quanto à tolerância ou não e quanto à manifestação de efeitos colaterais, não podemos aquilatar a adequação neste caso específico, mas fica consignado que há um medicamento padronizado e distribuído gratuitamente no SUS para o mesmo sintoma.

Nesse contexto, estritamente programático assistencial, e não clínico individual, podemos identificar que a prescrição medicamentosa em litígio definida pela resolução do judiciário, em realidade, está contemplada pelas normas e protocolos definidos pelo SUS.

Então para que a determinação judicial, se, em princípio, todos os medicamentos na ação judicial têm um análogo padronizado dentro do SUS?

O conflito que se apresenta está diretamente relacionado aos princípios do SUS de universalidade versus equidade. Estes princípios primordiais têm sido garantidos na assistência farmacêutica por meio da definição e pactuação entre as três esferas de governo para garantir os três grupos de medicamentos especificados acima, quais sejam: os da atenção básica, os estratégicos e os excepcionais. Estes três grupos de patologias abarcam os de maior freqüência e maior relevância e transcendência em termos de saúde pública brasileira. Recursos financeiros consideráveis e com incremento exponencial têm sido investidos para garantir a universalidade da atenção.

No entanto, tendo em vista que todo o provimento de medicamentos no sistema tem a mesma fonte de financiamento, temos um dilema. Ao prover, via judicial, medicamentos não padronizados e habitualmente mais caros, sem evidências que os efeitos na doença sejam realmente melhores, estaremos destinando mais recursos per capita a poucos em detrimento de garantir para a maioria os medicamentos essenciais para controle das doenças mais freqüentes.

Por conseguinte, toda vez em que houver uma dispensação medicamentosa que esteja fora da padronização corremos o risco de alterar uma alocação de recursos financeiros para poucos em detrimento de benefícios que poderiam destinar-se a muitos cidadãos. Cabe lembrar que as padronizações e os protocolos clínicos estão baseados em evidências científicas comprovadas por análises estatísticas disponíveis na literatura científica.

Outro aspecto relevante a ser levado em conta nesse caso-problema analisado seria a inovação tecnológica, representada, no caso especifico, pelos novos medicamentos. Provavelmente, os medicamentos analisados neste breve comentário se encontram nesta situação. O que caberia analisar seria o quanto um medicamento, apesar de estar disponível no mercado, em pleno uso clínico privado, mas ainda sem validação pelo SUS, deva ser dispensado para um cidadão, por ordem judicial, em contraposição aos medicamentos padronizados e incorporados em protocolos clínicos validados. 
Em síntese o presente desafio do SUS está entre garantir o fundamental para toda a população brasileira e o de garantir o direito individual à saúde de alguns poucos indivíduos que conseguem por meio de uma decisão judicial a dispensação de medicamentos cujos custo e efetividade não são plenamente conhecidos e validados. Cabe lembrar, neste exemplo específi$\mathrm{co}$, que os medicamentos disponibilizados à população com esta mesma patologia estão baseados em análises de custo e de resultados alcançados por medicamentos conhecidos e dispensados gratuitamente nos distintos níveis de complexidade do SUS. 